\title{
Estudios
}

\section{El Banco de la República: historia, reformas y su autonomía a raíz de la Constitución de 1991}

\author{
Banco de la República [The Central Bank of \\ Colombia]: history, reforms and its autonomy \\ as a result of the 1991 Constitution
}

\author{
Manuela Alejandra Castro Peña ${ }^{1}$ \\ Daniela Fernanda Devia Peralta ${ }^{2}$
}

Recepción: 29/07/2021 • Aprobación: 23/08/2021 • Publicación: 25/11/2021

Para citar este artículo

Castro Peña, M. A., \& Devia Peralta, D. F. (2021). El Banco de la República: historia, reformas y su autonomía a raíz de la Constitución de 1991. Dos mil tres mil, 23, e326. https://doi.org/10.35707/dostresmil/23326
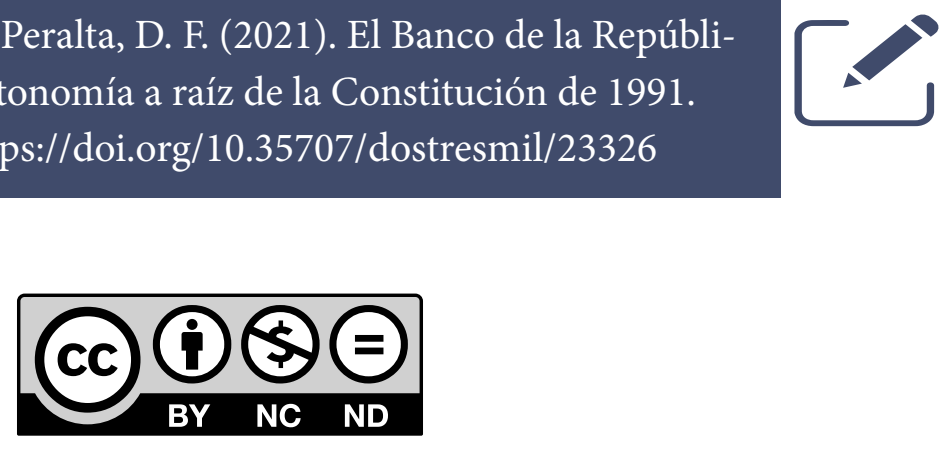

\footnotetext{
${ }^{1}$ Grupo de estudios de Derecho Penal Económico, Universidad de Ibagué, Ibagué, Colombia. Correo electrónico: 5120182081@estudiantesunibague.edu.co

${ }^{2}$ Grupo de estudios de Derecho Penal Económico, Universidad de Ibagué, Ibagué, Colombia. Correo electrónico: 5120181237@estudiantesunibague.edu.co
} 
Resumen. El presente escrito abarca los antecedentes de la creación del Banco de la República, destacando las diferentes misiones que dieron origen al Banco Nacional y el Banco Central, los cuales permitieron la conformación del Banco de la República en el año 1923. Adicionalmente, se resalta la figura del Banco dentro de la Constitución Política de 1991, ya que esta le brinda las bases de una amplia autonomía tanto administrativa, patrimonial y constitucional. A partir de allí se expide la Ley 31 de 1992 y el Decreto 2520 de 1993, los cuales alcanzan un mayor desarrollo a lo consagrado en la Carta Política en cuanto a la figura del Banco de la República.

Abstract. This document covers the antecedents of the creation of Banco de la República, highlighting different missions that gave rise to the National Bank and the Central Bank, which allowed the formation of Banco de la República in 1923. Additionally, the figure of the Bank within the Political Constitution of 1991, since this provides the bases of a broad administrative, patrimonial, and constitutional autonomy. From there, Act $31^{\text {st }}$ of 1992 and Decree 2520 of 1993 are issued, which reach a greater development than what is enshrined in the Political Charter regarding the figure of Banco de la República.

Palabras claves

Banco de la República, Constitución Política, reformas, autonomía, economía.

Key words

Banco de la República [The Central Bank of Colombia], Political Constitution, reforms, autonomy, economy. 


\section{Introducción}

Como homenaje al trigésimo aniversario de la Constitución Política de Colombia, en el presente trabajo se desarrollará un estudio sobre el avance legal que ha tenido la economía en el espacio de tiempo comprendido entre 1880 con la creación del Banco Nacional, la creación del Banco de la República en 1923, pasando por la Constitución Política de 1886, hasta llegar a nuestra Constitución actual.

Para desarrollar mejor el tema, se analizarán las reformas constitucionales más importantes que impulsan el funcionamiento de la economía en el país, basándonos principalmente en la importancia que tiene el desarrollo jurisprudencial y doctrinal en el tema. Además de eso, se realiza una investigación de las reformas estructurales al Banco de la República, resaltando su importancia en el funcionamiento económico del país y su independencia.

Este escrito pretende resaltar el desarrollo económico dentro del marco legal, señalando la importancia que tiene la Constitución Política actual y sus reformas en torno a este tema; de igual forma, los antecedentes de la creación del Banco de la República, así como una aproximación histórica sobre sus diversos grados de autonomía y mandato a raíz de reformas constitucionales. Es necesario conocer los antecedentes legales existentes, debido a que ayudan a hacer un seguimiento al desarrollo que ha tenido el derecho en cuanto a las regulaciones económicas, llegando hasta el punto en que se encuentra el derecho económico hoy en día.

\section{Antecedentes a la creación del Banco de la República}

En 1880, el Gobierno de Rafael Núñez creó el denominado Banco Nacional mediante la Ley 39 de 1880 con autorización de préstamo, emisión, giro y depósito. Esta figura generó un descontento en el sector bancario privado, el cual se mostró renuente a suscribir acciones por lo que no fue posible cumplir con el propósito de ser una entidad con capital mixto; además de existir el pensamiento generalizado de que el Gobierno creó el Banco Nacional con el claro propósito de que este actuara como su banquero y promoviera el crédito público, lo cual se traducía en ser una entidad de crédito para el gobierno (Hernández, 2001).

En relación con estas funciones y el hecho de que también fuera el encargado de la emisión de billetes, condujo a su liquidación en 1894 por el Congreso de la República debido a un exceso en la capacidad de emisión, que posteriormente tuvo como consecuencia un incremento en la inflación.

Años más tarde, en 1905, el presidente Rafael Reyes decide establecer el Banco Central con el propósito de estabilizar la economía a raíz de lo sucedido con el Banco Nacional y el incremento en la inflación de más del $300 \%$ anual, a raíz de la recientemente finalizada Guerra de los Mil Días (Meisel, 2017). Sin embargo, al ser este un banco de similares características con el Banco Nacional solo funcionó durante cuatro años (1905-1909) hasta que perdió su capacidad de emisión, por lo que desde ese entonces hasta su liquidación cumplía las funciones de un banco privado. 


\section{Creación del Banco de la República}

En el año 1923, con los estragos causados por la Primera Guerra Mundial y la inflación causada por el mal manejo en la emisión del dinero, el Gobierno, en cabeza de Pedro Nel Ospina, ordenó la contratación de técnicos estadounidenses en materia económica para realizar un estudio sobre la realidad económica del país (Cárdenas, 2013). Es así como por medio de la misión Kemmerer se crea el Banco de la República a través de la Ley 25 de 1923.

Mediante esta ley se le confió de manera exclusiva la facultad de la emisión de la moneda, la administración de las reservas internacionales de la nación y la calidad de prestamista de última instancia del gobierno. De este modo, el banco se creó como una entidad mixta, con un capital inicial de $\$ 10000000$ distribuidos en $\$ 5000000$ por parte del Estado y $\$ 5000000$ por parte de particulares, bancos privados nacionales y extranjeros.

Adicionalmente, contaba con una autonomía respecto al ejecutivo ya que la ley consagró que la Junta Directiva del Banco debía estar conformada por "tres representantes del gobierno, cuatro de los bancos nacionales, dos de los bancos extranjeros y uno por los accionistas particulares" (Tirado, 1971). Los cuales serían encargados de fijar las tasas de intervención y descuento cuya finalidad radicaba en el control de las tasas de interés y de ejercer funciones de control y regularización monetaria, basados en los lineamientos de la ortodoxia financiera de la época (corriente de pensamiento económico prominente).

En este punto es importante resaltar que, a raíz de sus 98 años de historia, el Banco de la República ha experimentado numerosas reformas de carácter significativo que serán explicadas brevemente a continuación, dentro de las cuales encontramos principalmente: la segunda misión Kemmerer (1930), la misión Grove (1949), la constitución de la Junta Monetaria (1963), la nacionalización del Banco de la República (1973) y finalmente, la nueva constitución (1991).

\subsection{Segunda misión Kemmerer (1930)}

En el año 1930 se lleva a cabo la segunda misión Kemmerer, la cual dio como resultado la Ley 82 de 1931 mediante la cual se modifica la estructura de la Junta Directiva del Banco de la República, ya que se incorporan representantes de la Federación Nacional de Cafeteros, las Cámaras de Comercio y se hace formal la inclusión del ministro de Hacienda. Adicionalmente, se establece el peso como moneda obligatoria para las transacciones realizadas en el país y se regula el cambio de moneda nacional a extranjera.

\subsection{Misión Grove (1949)}

La misión Grove, dirigida por Daniel Grove de la Reserva Federal de Nueva York, recomendó al Banco de la República hacer uso de más herramientas para la regularización de la oferta monetaria y la canalización del crédito, con el propósito de generar un incentivo al desarrollo económico. De este modo, se le concedió al banco la facultad de fijar cupos de crédito de emergencia, fomento, especial u ordinario y de realizar variaciones en las tasas de interés y descuento 
a los préstamos. Asimismo, se decidió prorrogar el término de duración del banco y, de igual manera, su exclusividad para la emisión de moneda por 20 años más (desde 1953) e incluir a los gremios en una mayor participación para conocer los intereses de los distintos sectores de la economía.

\subsection{Constitución de la Junta Monetaria (1963)}

La constitución de la Junta Monetaria representó, indudablemente, uno de los cambios más importantes hasta la Constitución de 1991, ya que estaba conformada por el ministro de Hacienda (quien presidía la junta), el ministro de Agricultura, el gerente del Banco de la República, el ministro de Desarrollo y el jefe del Departamento Nacional de Planeación. Es así que la creación de la Junta Monetaria devolvió al Estado las funciones que antes estaban en cabeza de la Junta Directiva, de carácter privado.

De esta manera, "se asignó al Estado el estudio y la adopción de las políticas cambiaria, monetaria y crediticia, dejando a la junta del Banco solo la ejecución de dichas políticas" (Banco de la República, s.f.a). Lo cual se traduce en que hubo una ruptura del balance entre el Ejecutivo y los intereses del sector privado, en cuanto al manejo por parte del Estado y los representantes del sector privado, ya que, al relegarse la Junta Directiva a únicamente el cumplimiento de las políticas adoptadas por la Junta Monetaria, se le concedió al Estado el monopolio de la emisión y de las políticas cambiaria y crediticia.

\subsection{Nacionalización del Banco de la República (1973)}

En el año 1973 se toma la decisión de nacionalizar el Banco de la República con la compra de casi la totalidad de las acciones por parte del Gobierno, dejando exclusivamente una a cada banco accionista. Sin embargo, se decidió mantener la participación en la Junta Directiva tanto de representantes del gobierno como de los sectores de la producción y distribución, así como los sectores exportador, consumidor y bancario.

Las reformas al sistema monetario y al Banco Emisor, contenidas en la Ley 7 y el Decreto 2617, culminaron con la oficialización del capital del Banco de la República, ya que el Estado pasó a ser propietario de la casi totalidad de sus acciones. Así mismo, se transformó en entidad de derecho público económico cuyas funciones no son delegables. (Banco de la República, s.f.b).

Esto quiere decir que el Estado, al ser propietario de poco menos de la totalidad de las acciones del Banco de la República, oficializó su capital y se transformó en una entidad de derecho público económico. Adicionalmente, reformó el sistema monetario y al banco emisor mediante la Ley 7 de 1973 y el Decreto 2617 de 1973.

\subsection{La reforma constitucional de 1991}

Los elementos esenciales que constituyen el Estado social de derecho, forma que se adoptó con la expedición de la Constitución Política de 1991, es la necesidad de obtener por parte del 
Estado un direccionamiento de la economía, sin perjuicio de iniciativas privadas. Esos cambios de la estructura económica se pueden llevar a cabo siempre y cuando vaya en dirección al desarrollo social.

Debido a esto, es necesaria la existencia de una regulación constitucional donde el Estado se encargue de orientar todos los procesos económicos, garantizando así la presencia del ordenamiento jurídico en dichos procesos. Según lo expone el doctrinante español Ángel Ganorrera, no es más que "el reflejo de esa convicción típica del Estado social según la cual la economía ya no es un sistema espontáneo, perfecto y autorregulado, sino que necesita constante tutela del Estado regulador" (1980, p. 419).

Esta Constitución, haciendo una comparación con las que la anteceden, es una constitución económica que brinda una importancia desde la misma Carta Política en torno a este pilar fundamental de la sociedad. Se configura uno de los tantos cambios que trae consigo esta reforma constitucional, además de las ya conocidas, como el amplio catálogo de derechos fundamentales, la implementación de mecanismos de participación ciudadana, entre otros muchos avances en cuanto a garantías para los colombianos.

Para la emisión de la Constitución Política de Colombia, la Asamblea Nacional Constituyente introdujo varios cambios al sistema bancario que existía en el país. En las ponencias y discusiones en torno a los cambios que se pretendían efectuar en torno al Banco de la República participaron personas de distintas índoles políticas e ideológicas, y a pesar de esto, todas concordaban con una misma verdad: era necesario dotar al Banco de autonomía si querían reducir la inflación por la que atravesaba el país y que en la década de los años noventa era alta y estable frente a los parámetros internacionales.

Para poder llegar al punto de autonomía que se conoce hoy en día, se presentó una discusión que se centró en cómo el Banco de la República coordinaría sus políticas con el Gobierno; esto, en razón a que se veía como amenazante que un órgano externo al Ejecutivo tuviera un mandato tan amplio en materia económica. Teniendo en cuenta, además, que la Constitución vigente en ese momento (1886) era de una tendencia netamente presidencialista y que el presidente de la República tenía la libertad de intervenir de forma continua en las decisiones que el Banco tomara.

Uno de los cambios más radicales, que aseguraban la autonomía tan deseada y buscada del Banco de la República, es la eliminación del poder que tenía de financiar a través del fomento de fondos a sectores particulares, uno de los mecanismos más usados para financiar planes de gobierno o lidiar con problemas políticos, sociales o sectoriales; esto hacía que el Banco y el Gobierno tuvieran una estrecha dependencia. De igual manera, la apropiación de recursos como fuente presupuestal (Cuenta Especial de Cambios), así se ve la necesidad de crear la Junta Directiva como autoridad monetaria, cambiaria y crediticia, características que aún conserva.

En cuanto a la naturaleza del Banco, se optó por la ruptura de la clásica división de las tres ramas del poder público. Se añadió una claridad en cuanto a la existencia de órganos 
independientes y autónomos que cumplirían funciones estatales, esto se encuentra en el artículo 113 de la Carta Política.

El objetivo principal por el cual se consagran las funciones del Banco y de su Junta Directiva en el régimen constitucional es que, si se quisiera hacer alguna modificación en cuanto al objetivo, naturaleza o función, esto signifique un cambio a nivel constitucional con todos los procesos legales requeridos para ello. Este, es sin duda, uno de los puntos más favorables con los que cuenta el Banco Central en la actualidad.

En total se radicaron 131 proyectos que se podían presentar de manera individual o en grupos, venían acompañados de una motivación completa con base a las razones por las cuales deberían ser incluidos en la nueva Constitución, una contextualización histórica y un articulado para ser incluido en la Carta Política.

Después de recibir los proyectos, cada comisión debía distribuir entre los encargados de redactar las ponencias; estas ponencias recogían las discusiones de las comisiones y pasaban a plenarias para la votación de la reforma.

\subsection{Expedición de la Ley 31 de 1992}

El 29 de diciembre de 1992, el Congreso de Colombia expidió la Ley 31 por la cual se establecen las normas a las que deberá sujetarse el Banco de la República para el ejercicio de sus funciones, el Gobierno para señalar el régimen de cambio internacional, para la expedición de los estatutos del Banco y para el ejercicio de las funciones de inspección, vigilancia y control del mismo, se determinan las entidades a las cuales pasarán los Fondos de Fomento que administra el Banco $\mathrm{y}$ se dictan otras disposiciones.

Dentro de esta ley se prevé unas condiciones precisas, unas de ellas comprenden la prohibición de otorgar créditos y garantías a entidades privadas o a particulares. Se excluyen los créditos de apoyo transitorios a establecimientos de créditos en última instancia, esto comprende una de las funciones concedidas por la Constitución al Banco.

\subsection{Decreto 2520 de 1993}

Al igual que la Ley 31 de 1992, este decreto fue expedido exclusivamente para regular todo lo relacionado con el Banco de la República. En este decreto se expiden los estatutos del Banco y constituyen lo que es el marco legal de funcionamiento de la Banca Central de Colombia.

Fue expedido el 14 de diciembre de 1993 por el en ese entonces presidente de la República, César Gaviria, haciendo uso de sus facultades dadas por el artículo 372 de la Constitución Política de 1991, nueva para ese entonces. Este es un decreto de tipo ordinario donde se estipulan los estatutos del Banco de la República. 


\section{La autonomía del Banco de la República}

Como se vio anteriormente, gracias a las reformas constitucionales, el marco legal que rige la economía nacional y en especial todo lo que tiene que ver con el Banco de la República como banco central, ha hecho que este posea una autonomía bastante importante en la actualidad. Esta autonomía se basa en la capacidad para realizar un análisis libre de los fenómenos monetarios, diseñar y aplicar políticas a su cargo que se ajusten al desarrollo eficiente de todas las funciones que la constitución y la ley impone.

Esa autonomía tiene dos misiones importantes: primero, una estabilidad institucional interna al no estar bajo la sujeción a otras instancias estatales. Segundo, brindar credibilidad en la toma de decisiones independientes y sin intervención de intereses del gobierno.

Sin embargo, como presidente de la Junta Directiva se encuentra el ministro de Hacienda de turno, para coordinar la armonía entre la economía general del gobierno y las funciones del Banco. Por otro lado, en el artículo 150 numeral 22 de la Constitución "Funciones del Congreso mediante leyes" se establece que el Congreso tiene como obligación "expedir las leyes relacionadas con el Banco de la República y con las funciones que compete desempeñar a su Junta Directiva". Estas dos premisas tienen como objetivo realizar una coordinación gobierno-banco en el desarrollo de sus funciones.

No obstante, esta competencia otorgada constitucionalmente al Congreso de la República se encuentra condicionada en el artículo 154 de la Constitución Nacional, el cual consagra que en las leyes concernientes al Banco de la República debe ser el Gobierno quien presente la iniciativa legislativa para dictarlas o reformarlas.

Hernando Hernández Quintero afirma que:

El Banco de la República es una persona jurídica de derecho público que funciona como órgano estatal de rango constitucional, de naturaleza propia y especial, con autonomía administrativa, patrimonial y técnica, sujeto a un régimen legal propio y que ejerce funciones de banca central. (2020, p. 72)

En sentencia proferida el 28 de octubre de 2004, radicación 66001-23-31-000-2001-01278-01, número interno 13995, consejera Ponente: Dra. María Inés Ortiz Barbosa y ratificado por la sentencia proferida el 25 de noviembre de 2004, radicación 66001-23-31-000-2000-0817- 01, número interno 13347, consejero Ponente: Dr. Héctor J. Romero Díaz, se establece que:

[...] El Banco de la República de una parte no se encuentra relacionado dentro de las entidades que hacen parte de la estructura del sector financiero y de otra no capta dineros del público para realizar operaciones de crédito, razón por la cual carece de sustento legal pretender considerarlo como integrante del sector financiero, más aún cuando es un órgano del Estado, con funciones de naturaleza única y régimen legal propio [...]. (Sentencia 66001-23-31-000-2001-01278-01, 2004, s.p.). 


\section{Naturaleza del Banco de la República}

Como resultado de un amplio desarrollo normativo y jurisprudencial, resaltando la expedición de la Constitución Política de 1991, se ha podido establecer la naturaleza del Banco de la siguiente forma:

- La Ley 31 de 1992 en el artículo $1 .^{\circ}$ expone su naturaleza y objeto:

El Banco de la República es una persona jurídica de derecho público, continuará funcionando como organismo estatal de rango constitucional, con régimen legal propio, de naturaleza propia y especial, con autonomía administrativa, patrimonial y técnica. El Banco de la República ejercerá las funciones de banca central de acuerdo con las disposiciones contenidas en la Constitución Política y en la presente Ley. (Ley 31 de 1992).

- El Decreto 2520 de 1993, artículo $1 .^{\circ}$ - nombre, naturaleza y objetivo- establece la misma naturaleza y objeto que se encuentran en la Ley anteriormente mencionada, además, adiciona que "el Banco de la República ejercerá las funciones de banca central de acuerdo con las disposiciones contenidas en la Constitución Política, en la Ley 31 de 1992 y en estos Estatutos".

- La Sentencia C- 050 de 1994 hace alusión a la naturaleza del Banco de la siguiente forma:

La naturaleza del Banco de la República como órgano constitucional autónomo e independiente, instituido para el cumplimiento de funciones técnicas, es fiel reflejo del pensamiento constituyente:

La autonomía administrativa y técnica especial dentro de la estructura del Estado, permite establecer que el Banco Central no forme parte de las ramas Legislativa, Ejecutiva, Jurisdiccional, Fiscalizadora o Electoral del Poder Público, sino que debe ser un órgano del Estado de naturaleza única, que por razón de las funciones que está llamado a cumplir, requiere de un ordenamiento y organización especiales, propio, diferente del común aplicable a las demás entidades públicas o privadas.

Dicha naturaleza del Banco y, por ende, la razón de su normatividad, se justifican porque se trata de una institución que debe tener en cuenta, ante todo, el carácter eminentemente técnico y por lo demás complejo de los problemas monetarios y cambiarios que maneja. El Banco Central debe ser el órgano al que le corresponda la dinámica de la organización monetaria de la economía para poner en funcionamiento el sistema, los controles y la dirección de la moneda y para ello, debe actuar con identidad propia, con un régimen legal y operativo distinto y autónomo, pues no de otra forma podría poner en práctica eficiente y oportunamente, las medidas monetarias que por Ley está llamado a dictar y ejecutar. (Sentencia C- 050, 1994, s.p.).

En los diversos pronunciamientos donde se establece la naturaleza del Banco se llega al mismo punto: su naturaleza se deriva a la independencia de las ramas del poder público, su descentralización e independencia administrativa; dicha naturaleza es considerada como única en razón a sus funciones, se requiere de un ordenamiento interno distinto y que difiere de otras entidades de orden público. 
Dentro de la Sentencia C-050 de 1994 se resalta que una de las mayores innovaciones que trajo consigo la expedición de la Constitución Política de 1991 fue:

Haber elevado al Banco de la República a la categoría de órgano del Estado con rango constitucional, concebido como persona jurídica de derecho público económico, con autonomía patrimonial, técnica y administrativa, sujeta a un régimen especial, con el propósito primordial de ejercer las funciones de banca central. (Sentencia C-050, 1994, s.p.).

\section{Autonomía constitucional}

La autonomía que le brinda la Constitución Política al Banco de la República inicia con el artículo 113 de la Carta, donde se establecieron las tres ramas del poder público independientes la una de la otra, con funciones específicas y deja al Banco de la República como un órgano especializado, autónomo e independiente a esas ramas de poder. Se instauró que, si bien son independientes, colaboran armónicamente para alcanzar los fines del Estado.

El siguiente apartado constitucional que refuerza esa autonomía se encuentra en el título XII, capítulo VI, de la banca central, donde expresan que "sujeto a un régimen legal propio", "ejercerá funciones de banca central". Además, en el artículo 372 se indica a la Junta Directiva, resaltándola como la organización que toma decisiones.

\subsection{Objetivo constitucional}

Dentro del Decreto 2520 de 1993 se establece un objetivo constitucional para el Banco de la República, haciendo una referencia que, si bien se cuenta con una autonomía constitucional, todo lo que se haga dentro de la Junta Directiva debe estar encaminado hacia el cumplimiento de objetivos constitucionales, para darle su lugar a la Carta Política y la supremacía que esta tiene dentro del ordenamiento jurídico colombiano.

El artículo 2 del Decreto 2520 establece lo siguiente:

El Banco de la República a nombre del Estado velará por el mantenimiento de la capacidad adquisitiva de la moneda conforme a las normas previstas en el artículo 373 de la Constitución Política y en la Ley 31 de 1992. Parágrafo. Para cumplir este objetivo la Junta Directiva del Banco adoptará metas específicas de inflación que deberán ser siempre menores a los últimos resultados registrados, y utilizará los instrumentos de las políticas a su cargo y hará las recomendaciones que resulten conducentes a ese mismo propósito.

\section{Funciones constitucionales del Banco de la República}

\subsection{Sentencia C-719 de 2004}

Dentro de la Sentencia C-719 de 2004 se establece que, si bien el Banco cuenta con una autono-

mía a la hora de llevar a cabo sus funciones, este debe hacerlo dentro de los marcos señalados por el legislador, respetando siempre el principio de legalidad. 
Desde el punto de vista material la autonomía del Banco de la República se halla limitada por la obligación constitucional que tiene esa institución de coordinar sus funciones con las de otras autoridades para que el Estado Colombiano pueda cumplir los fines previstos por la Carta.

Esta exigencia está concebida como una restricción y no una autorización por parte del legislador para ampliar las funciones del Banco.

Esta misma sentencia menciona las funciones básicas del Banco de la República, que además de comprender las consagradas en el artículo 371 de la Constitución Política de 1991, que se mencionarán a continuación, también está llamado a cumplir aquellas funciones que el legislador, en ejercicio de sus competencias, asignadas por la Constitución, determine. Se establece de la siguiente forma:

Como banca central, como autoridad monetaria, cambiaria y crediticia, así como en cumplimiento de las funciones básicas adicionales a la que invoca el actor, - para no hacer mención de las funciones que en ejercicio de su potestad de configuración el Legislador le atribuya-, es claro que el Banco de la República está llamado a entrar en relación con personas jurídicas públicas y privadas que no necesariamente corresponden a la categoría de establecimientos de crédito.

\subsection{Sentencia C-827 de 2001}

Dentro de esta resolución, la Corporación reitera la situación del Banco de la República como órgano autónomo de las ramas del poder público, cuenta con funciones consagradas en la Constitución Política. Sin embargo, se establece que:

Como funciones básicas del Banco se enuncian las de regular la moneda, los cambios internacionales y el crédito; emitir la moneda legal; administrar las reservas internacionales; ser prestamista de última instancia y banquero de los establecimientos de crédito; y servir como agente fiscal del Gobierno. Todas estas funciones, aclara la disposición superior, se ejercerán en coordinación con la política económica general. (Sentencia C-827, 2001, s.p.).

\subsection{Sentencia C-566 de 2000}

A diferencia de las demás decisiones de la Corte, dentro de esta sentencia se observa un mayor desarrollo en torno a las funciones técnicas del Banco, de la siguiente forma:

Adicionalmente, en atención a la naturaleza del Banco y a las particulares funciones técnicas que le corresponde cumplir, la Constitución prevé un sistema de control especial en cabeza del Presidente de la República, que deberá ser ejercido de acuerdo con los parámetros trazados por el legislador. Así, se consagra en el último inciso del artículo 372 de la Constitución: "El Presidente de la República ejercerá la inspección, vigilancia y control del Banco en los términos que señale la ley". (Sentencia C-566, 2000, s.p.). 


\section{Funciones constitucionales}

Como parte fundamental de esa autonomía constitucional con la que cuenta el Banco de la República, la Carta Política le designó un catálogo de funciones que se encuentran consagradas en el artículo 371 de la misma, a continuación, se explicarán las funciones más representativas:

\subsection{Emisión de moneda, determinación y características de la moneda legal}

Para poder analizar con mayor precisión esta función, es necesario hacer una remisión a la Ley 31 de 1992. En el artículo 8 se establece de forma breve las características de la moneda: "La moneda legal expresará su valor en pesos de acuerdo con las denominaciones que determine la Junta Directiva del Banco de la República y será el único medio de pago de curso legal con poder liberatorio ilimitado".

De esta forma, una de las funciones más importantes y por ello más conocida, es la de emisión de moneda, determinación y características de la moneda legal, lo cual supone un atributo más allá de una función constitucional. Es exclusivo e indelegable al Banco de la República, la cual cuenta con la autorización del Congreso y se basa en realizar la impresión, destrucción, cambio y puesta en circulación de especies monetarias.

Esta función va ligada con el principal objetivo de la política monetaria, la cual es "preservar la capacidad adquisitiva de la moneda, en coordinación con la política económica general, entendida como aquella que propende por estabilizar el producto y el empleo en sus niveles sostenibles de largo plazo" (Banco de la República, s.f.c).

\subsection{Banquero y prestamista de última instancia de los establecimientos de crédito}

La función constitucional conocida como Banquero de Bancos se basa en la prestación de un conjunto de servicios banqueros, que contribuyen a la estabilidad financiera y brindan un soporte a otras entidades bancarias en pro del buen funcionamiento de los sistemas de pago.

Las funciones específicas son: servicios bancarios prestados a la nación para el manejo de su liquidez, sistemas de negociación, acceso de pagos por parte de entidades financieras y una política financiera tanto nacional como internacional. Con esta función se puede corroborar la autonomía que reviste al Banco de la República, pues las decisiones que toma, además de estar ajustadas a la ley, están sometidas solo a la voluntad de este órgano.

\subsection{Administrar las reservas internacionales}

Esta función se basa en intervenir, custodiar, manejar y disponer de los activos de reserva. Estas actuaciones del Banco de la República tienen como finalidad dirigir esas reservas internacionales de manera que estén disponibles cuando se requiera su utilización.

Dichas reservas sirven para garantizar la disponibilidad cuando se requiera realizar pagos al exterior, contar con los recursos necesarios. Por ejemplo, en actividades comerciales como 
las importaciones y los intereses de la deuda contraída por nacionales en ese mercado internacional debido a las exportaciones.

\subsection{Agente fiscal del Gobierno}

El Banco de la República, como ente independiente, realiza cierta colaboración con el Gobierno Nacional en torno a decisiones económicas, tales como participar en contrataciones de los créditos tanto internos como externos que celebre el gobierno; por otro lado, administra algunos bonos y títulos emitidos por este. Dentro de esta función, el Banco también puede recibir en depósito fondos de entidades públicas y nacionales.

\subsection{Prestamista de última instancia de los establecimientos de crédito}

Esta última función del Banco de la República surge debido a los grandes riesgos que tiene la actividad financiera, esos riesgos son eventuales crisis de confianza que generan pérdida de liquidez a esos establecimientos, así un pánico financiero. Dicha situación genera una peligrosa alteración al sistema de pagos de créditos; el Banco Central ayuda a estos establecimientos a través de celebración de contratos de descuento y redescuento de títulos valores bajo las condiciones que indique la Junta Directiva, con el fin de brindar apoyos transitorios de liquidez a los establecimientos que atraviesen una situación de este tipo.

La Sentencia C-566 de 2000, en cuanto a las funciones del Banco de la República, establece que, "a diferencia del control que ejerce la Contraloría que es posterior, selectivo y referido exclusivamente a actividades de gestión fiscal, el que en virtud del artículo 372 de la Carta le corresponde desarrollar al presidente de la República", como ya se ha indicado:

Es un control permanente, de carácter administrativo, que recae sobre todos los actos, hechos y operaciones que realice el Banco en desarrollo de las funciones que le compete cumplir, es decir, sobre todos aquellos asuntos propios del manejo de ese organismo técnico especializado. (Sentencia C-566, 2000, s.p.).

Sin perjuicio del control que puedan ejercer otras autoridades, el presidente también debe velar porque en el cumplimiento de las funciones asignadas al Banco todos los empleados respeten la Constitución y la ley; claro está, dentro de los parámetros y directrices que para ello le ha fijado el legislador.

\subsection{Funciones del Decreto 2520 de 1993}

Debido a que a través de este decreto se expiden los estatutos del Banco de la República, se establecen unas funciones que, si bien no son tan específicas que las brindadas por la Constitución Política, engrosan el amplio catálogo. Estas se encuentran en el artículo 13, y son las siguientes: 
a. A solicitud del Gobierno, actuar como agente fiscal en la contratación de créditos externos e internos y en aquellas operaciones que sean compatibles con las finalidades del Banco;

b. Otorgar créditos o garantías a favor del Estado en las condiciones previstas en el artículo 373 de la Constitución Política;

c. Recibir en depósito fondos de la Nación y de las entidades públicas. La Junta Directiva señalará los casos y condiciones en que el Banco podrá efectuar estas operaciones;

d. Servir como agente del Gobierno en la edición, colocación y administración en el mercado de los títulos de deuda pública;

e. Prestar al Gobierno Nacional y a otras entidades públicas que la Junta determine, la asistencia técnica requerida en asuntos afines a la naturaleza y funciones del Banco.

\section{Funciones específicas}

\subsection{Sentencia C-485 de 1993}

Dentro de esta sentencia se establece que es el presidente de la República, por mandato constitucional (y no el Banco de la República), el encargado de representar internacionalmente al Estado colombiano. Adicionalmente, aclara que en ninguna circunstancia puede la ley de naturaleza ordinaria suprimir esta facultad constitucional en cabeza del presidente de la República, so pena de quebrantar la característica diferenciadora de República Unitaria esencial en el Estado colombiano.

Es decir, que al no poderse adscribir por medio de una ley ordinaria al Banco de la República la función de representar internacionalmente al Estado colombiano ante los organismos de carácter financiero sin vulnerar los artículos 121, 136 y 189 constitucionales, tampoco entraría en la competencia de la Junta Directiva del Banco fijar los criterios que orienten su ejercicio.

\subsection{Sentencia C-566 del 2000}

La Sentencia C-566 del 2000 establece que el presidente de la República, con fundamento en el artículo 372 constitucional, tiene la obligación de realizar un control permanente en materia administrativa sobre todas las operaciones, los actos y los hechos realizados por el Banco de la República en el desarrollo de las funciones que le corresponden, es decir, sobre cada uno de los asuntos que sean propios de su manejo. Adicionalmente, el presidente debe velar por el efectivo cumplimiento de las funciones del mismo banco y el respeto por la Constitución Política y la ley; esto independientemente del control que puedan ejercer sobre el mismo otras autoridades.

\section{Autonomía administrativa}

Dentro de la autonomía administrativa, la Corte en su Sentencia C-050 de 1994 establece que:

La autonomía administrativa del Banco significa que no pertenece a ninguna de las ramas del poder público, ni a los órganos fiscalizador o de control o electoral, sino que es un órgano autónomo e independiente que aun cuando forma parte del Estado, tiene una naturaleza única que, en razón a sus 
funciones, requiere de un ordenamiento y organización especiales, que difiere del común aplicable a las demás entidades públicas y privadas. (Sentencia C-050, 1994, s.p.).

Para reforzar dicha autonomía, se debe resaltar la labor de la Junta Directiva, la cual se encuentra amparada constitucionalmente en el artículo 372.

\subsection{Junta Directiva del Banco de la República}

La Junta Directiva del Banco de la República fue instituida por la Constitución Política y la Ley 31 de 1992. La autonomía administrativa se encuentra en dicha junta como autoridad monetaria, crediticia y cambiaria del país, cuya función principal es representar el interés nacional en relación con el funcionamiento económico. Tiene, además, por mandato constitucional, a su cargo la dirección y ejecución de las funciones del Banco (Banco de la República, s.f.d).

El Decreto 2520 de 1993, en su artículo 5, establece a la Junta Directiva como autoridad monetaria, cambiaria y crediticia. De esta forma, cumplirá las funciones previstas en la Constitución y la Ley 31 de 1992, mediante disposiciones de carácter general.

Tales funciones se ejercerán en coordinación con la política económica general prevista en el programa macroeconómico aprobado por el Consejo Nacional de Política Económica y Social, CONPES, siempre que esta no comprometa la responsabilidad constitucional del Estado, por intermedio del Banco de la República, de velar por el mantenimiento de la capacidad adquisitiva de la moneda. (Ley 31 de 1992, artículo $\left.4 .^{\circ}\right)$.

Las funciones anteriormente mencionadas de la Constitución y la Ley 31 de 1992, respaldadas por los estatutos del mismo banco, Decreto 2520 de 1993, tienen como objetivo el mantenimiento de la capacidad adquisitiva monetaria que está a cargo de la Junta Directiva por mandato constitucional. Los miembros de la junta representan exclusivamente el interés general de la Nación y son los encargados de que esas funciones se cumplan a cabalidad.

\subsection{Conformación de la Junta Directiva}

La Junta Administrativa estará integrada por siete (7) miembros y se conforma de la siguiente manera: el ministro de Hacienda y Crédito Público quien ejercerá como presidente, cinco miembros de dedicación exclusiva nombrados por el presidente de la República y el gerente general del Banco nombrado por los miembros anteriores. El periodo de ejercicio se divide en periodos fijos de cuatro años, los miembros de dedicación exclusiva, prorrogables por dos veces. Ninguno de los miembros puede permanecer por más de tres periodos consecutivos.

\subsection{Funciones de la Junta Directiva}

La Constitución Política de 1991 estableció las funciones que deberá cumplir la junta como autoridad monetaria, crediticia y cambiaria: 
- Controlar el dinero que circula en la economía, evitando que se produzcan efectos como altos niveles de inflación o desempleo.

- Regular las tasas de interés que manejan los bancos con sus clientes, fungiendo así como autoridad crediticia.

- El encaje bancario que otros bancos e instituciones financieras deben mantener.

- Debe controlar el valor del peso colombiano frente a otras monedas extranjeras, actuando como autoridad cambiaria.

Por otro lado, la Ley 31 de 1992 dedica un capítulo entero a todo lo relacionado con la Junta Directiva del Banco, asignando otra amplia lista de atribuciones que tienen como fin el cumplimiento de los objetivos trazados de mantener la estabilidad económica del país. El artículo 16 del capítulo V atribuciones establece lo siguiente:

Al Banco de la República le corresponde estudiar y adoptar las medidas monetarias, crediticias y cambiarias para regular la circulación monetaria y en general la liquidez del mercado financiero y el normal funcionamiento de los pagos internos y externos de la economía, velando por la estabilidad del valor de la moneda. Para tal efecto, la Junta Directiva podrá:

a) Fijar y reglamentar el encaje de las distintas categorías de establecimientos de crédito y en general de todas las entidades que reciban depósitos a la vista, a término o de ahorro, señalar o no su remuneración y establecer las sanciones por infracción a las normas sobre esta materia. Para estos efectos, podrán tenerse en cuenta consideraciones tales como la clase y plazo de la operación sujeta a encaje. El encaje deberá estar representado por depósitos en el Banco de la República o efectivo en caja.

b) Disponer la realización de operaciones en el mercado abierto con sus propios títulos, con títulos de deuda pública o con los que autorice la Junta Directiva, en estos casos en moneda legal o extranjera, determinar los intermediarios para estas operaciones y los requisitos que deberán cumplir estos. En desarrollo de esta facultad podrá disponer la realización de operaciones de reporto (repos) para regular la liquidez de la economía.

c) Señalar, mediante normas de carácter general, las condiciones financieras a las cuales deberán sujetarse las entidades públicas autorizadas por la ley para adquirir o colocar títulos con el fin de asegurar que estas operaciones se efectúen en condiciones de mercado. Sin el cumplimiento de estas condiciones los respectivos títulos no podrán ser ofrecidos ni colocados.

d) Señalar, en situaciones excepcionales y por períodos que sumados en el año no excedan de ciento veinte (120) días, límites de crecimiento a la cartera y a las demás operaciones activas que realicen los establecimientos de crédito, tales como avales, garantías y aceptaciones.

e) Señalar en situaciones excepcionales y por períodos que sumados en el año no excedan de ciento veinte (120) días, las tasas máximas de interés remuneratorio que los establecimientos de crédito pueden cobrar o pagar a su clientela sobre todas las operaciones activas y pasivas, sin inducir tasas reales negativas. Las tasas máximas de interés que pueden convenirse en las operaciones en moneda extranjera continuarán sujetas a las determinaciones de la Junta Directiva. Estas tasas podrán ser 
diferentes en atención a aspectos tales como la clase de operación, el destino de los fondos y el lugar de su aplicación. Los establecimientos de crédito que cobren tasas de interés en exceso de las señaladas por la Junta Directiva estarán sujetos a las sanciones administrativas que establezca la Junta en forma general para estos casos.

f) Fijar la metodología para la determinación de los valores en moneda legal de la Unidad de Poder Adquisitivo Constante —UPAC—, procurando que ésta también refleje los movimientos de la tasa de interés en la economía.

g) Regular el crédito interbancario para atender requerimientos transitorios de liquidez de los establecimientos de crédito.

h) Ejercer las funciones de regulación cambiaria previstas en el parágrafo $1 .^{\circ}$ del artículo $3 .^{\circ} \mathrm{y}$ en los artículos 5. a 13, 16, 22, 27, 28 y 31 de la Ley 9. ${ }^{\text {a de } 1991 .}$

i) Disponer la intervención del Banco de la República en el mercado cambiario como comprador o vendedor de divisas, o la emisión y colocación de títulos representativos de las mismas. Igualmente, determinar la política de manejo de la tasa de cambio, de común acuerdo con el ministro de Hacienda y Crédito Público. En caso de desacuerdo, prevalecerá la responsabilidad constitucional del Estado de velar por el mantenimiento de la capacidad adquisitiva de la moneda.

j) Emitir concepto previo favorable para la monetización de las divisas originadas en el pago de los excedentes transitorios de que trata el artículo 31 de la Ley 51 de 1990.

k) Emitir concepto, cuando lo estime necesario y durante el trámite legislativo, sobre la cuantía de los recursos de crédito interno o externo incluida en el proyecto de presupuesto con el fin de dar cumplimiento al mandato previsto en el artículo 373 de la Constitución Política.

Las funciones de la Junta Directiva son un conjunto de atribuciones que tanto la ley como la Constitución Política establecen de forma muy específica para que el Banco de la República pueda funcionar de manera óptima debido a su importancia en la economía tanto nacional como internacional, respetando siempre la autonomía en las decisiones que se toman dentro del mismo.

\section{Conclusiones}

Para concluir, una de las reformas más importantes que trajo consigo la Constitución de 1991 es el reconocimiento que se le da a la economía, enfocándose en el Banco de la República, al brindarle una protección a nivel constitucional y legal, a través de la Ley 31 de 1992 y dotarlo de una autonomía en todos los aspectos; ganándose así el estatus de la primera constitución económica que tiene Colombia.

En cuanto al Banco de la República, una de las razones para la expedición de una nueva constitución era la de implementar un sistema de banca central autónoma a las ramas del poder público, que obviara las funciones que iban en pro de intereses gubernamentales; específicamente, crear un cuerpo administrativo cuyo objetivo sea únicamente velar por el funcionamiento del banco e imponer funciones amplias con el fin de que la economía fuera estable. 
A pesar de todas las dudas que giraban en torno a este ideal, se logró dotarlo de esa autonomía fundamentalmente constitucional y administrativa, que garantice que las funciones se desarrollarán en miras del interés general, velando, sin la inferencia del gobierno.

Al contar con una Junta Directiva propia, y la forma de elección de miembros que se estableció dentro de la Constitución, se garantiza que las decisiones no favorezcan en forma exclusiva al gobierno de turno, lo que brinda una sensación de bienestar económico del país; no es un banco dirigido a ayudar únicamente al gobierno. Está amparado constitucionalmente, recordando la importancia que tiene para el funcionamiento adecuado tanto de la economía nacional, como de la actividad bancaria en sí, incluyendo bancos privados.

\section{Referencias}

Banco de la República de Colombia. (s.f.a). Historia del Banco de la República. Reforma de 1963. Recuperado de https://www.banrep.gov.co/es/reforma-1963

Banco de la República de Colombia. (s.f.b). Historia del Banco de la República. Reforma de 1973. Recuperado de https://www.banrep.gov.co/es/reforma-1973

Banco de la República de Colombia. (s.f.c). Qué hacemos. Recuperado de https://www.banrep.gov.co/es/ el-banco/que-hacemos

Banco de la República de Colombia. (s.f.d). El nuevo ordenamiento del Banco y su Junta Directiva. Recuperado de https://www.banrep.gov.co/es/el-banco/historia/el-nuevo-ordenamiento-del-banco-ysu-junta-directiva

Cárdenas, J. (2013). Evolución histórica del Banco de la República en Colombia: una aproximación. Finanzas y Política Económica, 5 (2), 71-87. Recuperado de http://www.scielo.org.co/pdf/fype/v5n2/ v5n2a05.pdf

Colombia. Ley 25 de 1923. Orgánica del Banco de la República.

Colombia. Ley 82 de 1931. Reformatoria de la 25 de 1923, orgánica del Banco de la República.

Colombia. Ley 7 de 1973. Por la cual se regula sobre la emisión, se dan unas autorizaciones al Gobierno para celebrar un contrato, se adicionan las facultades de la Junta Monetaria y se dictan otras disposiciones.

Colombia. Decreto 2617 de 1973. Por el cual se adoptan normas sobre organización y funcionamiento del banco de la república. Diario oficial No. 34006.

Colombia. Ley 31 de 1992. Por la cual se dictan las normas a las que deberá sujetarse el Banco de la República para el ejercicio de sus funciones, el Gobierno para señalar el régimen de cambio internacional, para la expedición de los Estatutos del Banco y para el ejercicio de las funciones de inspección, vigilancia y control del mismo, se determinan las entidades a las cuales pasarán los Fondos de Fomento que administra el Banco y se dictan otras disposiciones. Diciembre 29, 1992. Diario Oficial n. ${ }^{\circ} 40.707$

Colombia. Decreto 2520 de 1993. Por el cual se expiden los Estatutos del Banco de la República. Diario oficial, n.o 41142. 
Constitución Política de Colombia. (1991). Bogotá, Colombia: Panamericana.

Ganorrera, A. (1980). El Estado español como Estado social y democrático de Derecho. España: Universidad de Murcia.

Hernández Quintero, H. A. (2020). Los delitos económicos en la actividad financiera. Bogotá, Colombia: Grupo Editorial Ibáñez.

Hernández Gamarra, A. (2001). La banca central en Colombia: Banco Nacional (1880), Banco Central (1905), Banco de la República (1923). Recuperado de https://www.banrepcultural.org/bibliotecavirtual/credencial-historia/numero-135/la-banca-central-en-colombia

Meisel-Roca, A. (2017) Antecedentes del Banco de la República, 1904 -1922. En J. D. Uribe-Escobar (Ed.), Historia del Banco de la República 1923 - 2015, 1-23. Recuperado de https://doi.org/10.32468/ Ebook.664-366-5

Sentencia C- 485 de 1993. Corte Constitucional de Colombia. Magistrado Ponente: Eduardo Cifuentes Muñoz.

Sentencia C-050 de 1994. Corte Constitucional de Colombia. Magistrado Ponente: Hernando Herrera Vergara.

Sentencia C-566 de 2000. Corte Constitucional de Colombia. Magistrado Ponente: Carlos Gaviria Díaz. Sentencia C-827 de 2001. Corte Constitucional de Colombia. Magistrado Ponente: Álvaro Tafur Galvis.

Sentencia C- 719 de 2004. Corte Constitucional de Colombia. Magistrado Ponente: Álvaro Tafur Galvis.

Sentencia n. ${ }^{\circ}$ 66001-23-31-000-2001-01278-01. Consejo de Estado de Colombia. Consejera Ponente: María Inés Ortiz Barbosa.

Tirado M., A. (1971). Siglo XX: 1900-1930; Empréstitos extranjeros, Banco de la República. En A. Tirado M. (2da. edición), Introducción a la historia económica de Colombia (pp. 231-240). Bogotá, Colombia: Universidad Nacional de Colombia-Dirección de Divulgación Cultural.

\section{Bibliografía recomendada}

Banco de la República de Colombia (s.f.). El Banco en la Constitución de 1991. Recuperado de https:// www.banrep.gov.co/es/el-banco/historia/el-banco-constitucion-1991

Banco de la República de Colombia (s.f.). Asamblea Nacional Constituyente-1991. Recuperado de https:// babel.banrepcultural.org/digital/collection/p17054coll28

Hernández, G. (2010). La jurisprudencia de la Corte Constitucional y la autonomía del Banco de la República. Recuperado de https://hdl.handle.net/20.500.12134/7002 